\title{
Copper Incorporation into CdS Thin Films by Ionic Exchange in an Aqueous Solution Process at Room Temperature
}

\author{
E. Flores-García, ${ }^{1}$ M. A. Hernández-Landaverde, ${ }^{2}$ P. González-García $(\mathbb{D})^{3}$ \\ and R. Ramírez-Bon ${ }^{2}$ \\ ${ }^{1}$ Centro de Ingeniería y Desarrollo Industrial, Av. Playa Pie de la Cuesta 702, Desarrollo San Pablo, 76130 Querétaro, \\ QRO, Mexico \\ ${ }^{2}$ Centro de Investigación y de Estudios Avanzados del IPN Unidad Querétaro, Apdo Postal 1-798, 76001 Querétaro, QRO, Mexico \\ ${ }^{3}$ CONACYT-CIDESI, Centro Nacional de Tecnologías Aeronáuticas (CENTA), \\ Carretera Estatal 200 Querétaro-Tequisquiapan km 23 No. 22547, 76270 Colón, QRO, Mexico
}

Correspondence should be addressed to P. González-García; pedro.gonzalez@cidesi.edu.mx

Received 28 February 2018; Revised 10 April 2018; Accepted 29 April 2018; Published 1 August 2018

Academic Editor: Christoph Krafft

Copyright (c) 2018 E. Flores-García et al. This is an open access article distributed under the Creative Commons Attribution License, which permits unrestricted use, distribution, and reproduction in any medium, provided the original work is properly cited.

\begin{abstract}
Cadmium sulfide (CdS) thin films were deposited, on glass substrates, at $70^{\circ} \mathrm{C}$ for 120 min using an ammonium-free chemical bath deposition process. After deposition, the films were placed in a $\mathrm{CuCl}_{2}$ solution for 45, 60, 75, and 90 min, respectively, for their ion exchange, generating $\mathrm{Cd}_{\mathrm{x}} \mathrm{Cu}_{1-\mathrm{x}} \mathrm{S}$ films. The obtained films were analyzed by X-ray diffraction, Raman spectroscopy, X-ray wavelength dispersion spectrometry, and scanning electron microscopy. The reference CdS films showed a homogeneous appearance and a yellowish color; elapsing the immersion time, the films changed their color showing a greenish appearance. The $\mathrm{X}$-ray analysis indicated that the CdS films developed a hexagonal structure with preferential orientation along the plane (002). During the ion exchange, a decrease in the intensity of the reflection (002) was observed as well as a slight displacement of this reflection towards higher values of $2 \theta$ derived from the substitution of $\mathrm{Cd}$ atoms by $\mathrm{Cu}$ atoms. The WDS analysis revealed that approximately $10 \%$ of the cadmium atoms were replaced by copper ones after $90 \mathrm{~min}$ of immersion.
\end{abstract}

\section{Introduction}

During the last three decades, the development and application of novel semiconductor materials has increased considerably. This positive trend is because of the versatility of semiconductor materials, whose properties allow for a wide range of technological applications such as diodes, photodetectors, thermistors, varistors, transistors, and solar cells among others. Such versatility of the semiconductor materials is based on the possibility to modify their electrical properties either by doping or by exposing to heat, light, and other external excitations. This enables the application of semiconductor devices for amplification, switching, and energy conversion. Silicon based semiconductors were the first materials used in this type of devices, but due to their high manufacturing costs, this type of technology is expensive as a consequence. Therefore, different research groups have focused their attention on other alternative semiconductor materials like those of the II-VI group chalcogenides family, which includes $\mathrm{ZnO}, \mathrm{CdS}, \mathrm{CdTe}, \mathrm{CdO}$, and others as alternative materials [1].

Metal chalcogenides, in thin film form, have been widely used in different applications as superconducting films, diamond-like films, magnetic films, microelectronic devices, surface modification, hard coatings, photoconductors, IR detectors, solar control, solar selective coatings, optical imaging, solar cells, optical mass memories, sensors, fabrication of large area photodiode arrays catalyst, and so on. [2]. Cadmium sulfide (CdS) is one of the most promising IIVI compounds because of its wide range of application in photovoltaic cell, optical filters and multilayer light emitting diodes, photodetectors, thin film field effect transistors, gas 
sensors, and transparent conducting semiconductor for optoelectronic devices [3]. Hence, CdS thin films have become an important material for their use as window layers in the fabrication of thin-film solar cells because of the presence of suitable photoconductivity, high optical transmittance in the visible and infrared regions, and compact and uniform morphology to avoid short circuit effects [4]. Several methods have been reported for the deposition of CdS films such as vacuum evaporation [5], sputtering [6], molecular beam epitaxy (MBE) [7], metal organic chemical vapor deposition (MOCVD) [8], electrodeposition [9], successive ionic layer adsorption and reaction (SILAR) [10], and chemical bath deposition (CBD) [11]. Among these, CBD is one of the most versatile techniques used for thin film growth because of its suppleness, relative low-cost operation, scaling, and high reproducibility [12]. In addition, the CBD technique is quite appropriate for the film deposition at large scale without the need of sophisticated infrastructure like high vacuum systems.

Deposition of CdS films by CBD is based on the formation of a solid phase from the slow release of $\mathrm{Cd}^{2+}$ and $\mathrm{S}^{2-}$ ions contained in an aqueous solution; subsequently, these ions condense on substrates suitably mounted within the precursor solution [13]. Also, it is known that most CdS films produced by the CBD technique exhibit a highly stable hexagonal phase with orientation preferential and growth columnar along the $c$-axis perpendicular to the substrate [14], introducing less grain boundaries parallel to the junction which can impede the flow of photogenerated excess carriers to the grid [15]. Nevertheless, different effects can take place during their coupling in semiconductor heterojunctions including delamination and diffusion.

In particular, related phenomena with the copper atoms diffusion in $\mathrm{Cu}_{\mathrm{x}} \mathrm{S} / \mathrm{CdS}$ heterojunctions have been widely studied since the $80 \mathrm{~s}$, focusing their attention in the partial or complete transformation of a CdS phase into a phase of $\mathrm{Cu}_{\mathrm{x}} \mathrm{S}$ [16-18]. Other studies have been performed about CdS thin films which are centered in the substitution of $\mathrm{Cd}$ atoms by copper atoms $[19,20]$, producing $\mathrm{CdS}: \mathrm{Cu}$ films with tunable properties in a wide range through a suitable composition. Therefore, in this work, the effect of the incorporation of copper substitutional atoms within hexagonal structure of the CdS through ionic exchange process in aqueous solution containing copper ions at room temperature was studied. The effect of immersion time over structural, morphological, and chemical properties of reference CdS films was evaluated.

\section{Experimental Details}

2.1. Deposition of the CdS Thin Films. CdS thin films were deposited on commercial glass slides $(26 \times 75 \times 1 \mathrm{~mm})$ using an ammonia-free chemical bath deposition process. The precursor solution, for the deposition of the CdS films, was prepared using a method reported previously by our research group, which consists in the sequential mixture of $25 \mathrm{ml}$ of $0.1 \mathrm{M} \mathrm{CdCl}_{2}, 20 \mathrm{ml}$ of $1 \mathrm{M}$ sodium citrate (SC), $5 \mathrm{ml}$ of $1 \mathrm{M} \mathrm{KOH}, 5 \mathrm{ml}$ of solution $\mathrm{pH} 10$ based borate to maintain constant $\mathrm{pH}$ value of solution during all deposition process, $10 \mathrm{ml}$ of $1 \mathrm{M} \mathrm{CS}\left(\mathrm{NH}_{2}\right)_{2}$ (thiourea), and enough deionized water to complete a total volume of $100 \mathrm{ml}$ [21]. Prior to deposition, glass substrates were cleaned using common detergent and water, rinsed with deionized water, and subsequently were placed in ultrasonic bath for $10 \mathrm{~min}$ using different solvents such as acetone, mixture of ethanol: xylene: acetone (ratio 1:1:1 in volume), and ethanol, respectively. Subsequently, five substrates were dried with high purity nitrogen gas and were placed vertically against the wall of $100 \mathrm{ml}$ beaker, and then the precursor solution was transferred to the beaker and introduced into a heated bath at $70^{\circ} \mathrm{C}$ during $120 \mathrm{~min}$ approximately. Finally, the substrates were removed from precursor solution, rinsed with deionized water, cleaned with wet cotton, and dried with nitrogen gas to remove the leftover material that could not be adhered to the substrate.

2.2. Copper Incorporation. CdS thin films, with thickness near to $140 \mathrm{~nm}$, were immersed in aqueous cationic solution $\left(\mathrm{CuCl}_{2}\right)$ and removed after $45,60,75$, and $90 \mathrm{~min}$. Here, the $\mathrm{CuCl}_{2}$ solution contained $0.34 \mathrm{ppm}$ of $\mathrm{Cu}^{2+}$. Finally, the samples were labeled as L1, L2, L3, and L4, respectively.

2.3. Structural and Optical Characterization. X-ray diffraction (XRD) patterns were recorded on a Rigaku Dmax 2100 diffractometer, using Seemann-Bohlin geometry and $\mathrm{Cu}$ target $(\lambda=0.156 \mathrm{~nm})$. The Raman spectra were acquired at room temperature in the frequency range of $100-800 \mathrm{~cm}^{-1}$ using a micro Raman Dilor Labram II with an Ar laser $(488 \mathrm{~nm})$ as excitation source. The thickness of the thin films was measured in ten different points using a $3 \mathrm{D}$ optical microscope Contour GT-K0 in PSI mode. The morphology and compositional analysis, by wavelength-dispersive X-ray spectroscopy (WDS) of the samples, were carried out using an electron probe microanalysis JEOL JXA-8530F.

\section{Results and Discussion}

3.1. Structural Properties. The CdS thin films obtained in this work presented uniform distribution on the substrate (observed by the eye), specular with light-yellow appearance and, also showed good adherence to the substrate. After immersion in the cationic solution, with the increase of the immersion time, the CdS films changed their appearance from yellowish to greenish color. This color change can be interpreted as the first evidence of the incorporation of copper atoms within crystalline structure of the cadmium sulfide. That is, $\mathrm{Cu}^{2+}$ ions can be incorporated into $\mathrm{CdS}$ thin films substituting $\mathrm{Cd}^{2+}$ by means of simple ion exchange process in aqueous solution, according to the following equation:

$$
\mathrm{CdS}+\mathrm{CuCl}_{2} \longrightarrow \mathrm{CuS}+\mathrm{CdCl}_{2}
$$

where, the cations ligated within their crystal host lattice can be substituted with those present in the solution.

Figure 1 shows the X-ray patterns obtained for the different samples, here is included the CdS reference film labeled as L0. As observed, all the patterns show an intense 


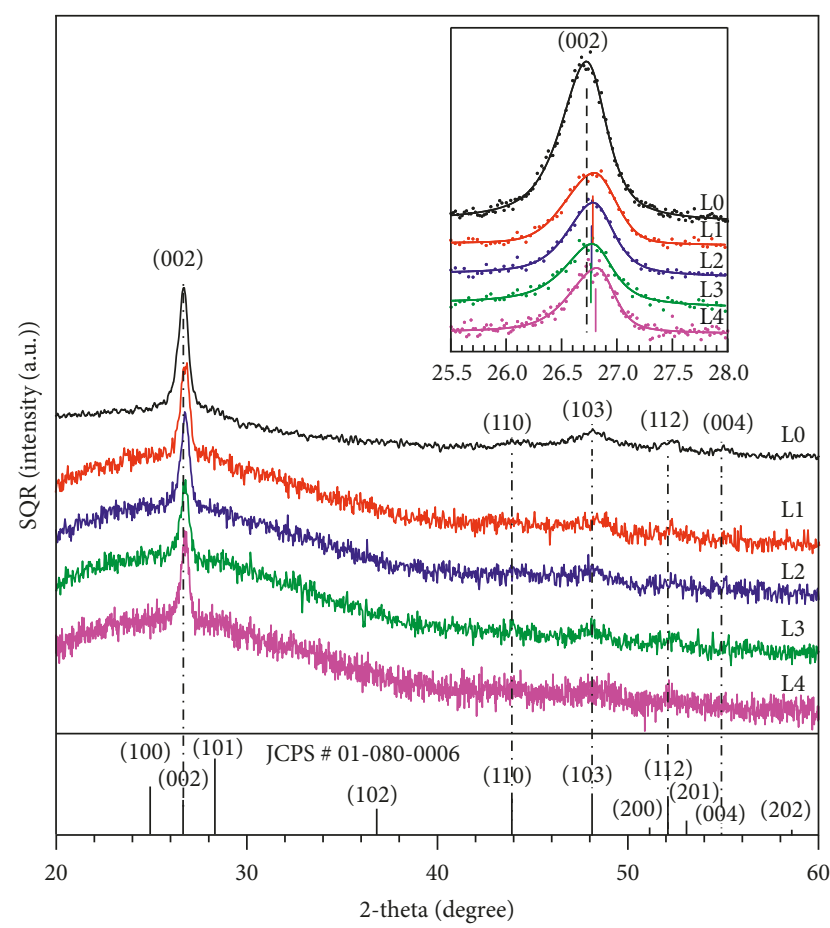

FIgURE 1: XRD patterns set for CdS: $\mathrm{Cu}$ films obtained by ionic exchange process in aqueous solution. The inset in the upper-right zone is an enlargement around the (002) reflection.

diffraction peak at $2 \theta \approx 26.7^{\circ}$, which could correspond to the (002) reflection of the CdS hexagonal phase or the (111) reflection of the CdS cubic structure. The predominance of this reflection in the XRD patterns indicates that the films are polycrystalline with high preferential orientation along the (002) or (111) crystalline direction. As well, the pattern of the CdS films show reflections located at $2 \theta \approx 44$ and $53^{\circ}$ that can be assigned to the (220) and (331) crystalline planes of the cubic phase (JCPS \#01-010-0454) or (110) and (112) planes of the hexagonal structure (JCPS \#01-080-0006) of CdS, respectively. However, a reflection located at $2 \theta \approx 48^{\circ}$, which explicitly corresponds to the (103) reflection of the hexagonal phase of $\mathrm{CdS}$ is also detected. Presence of this last reflection might suggest that the precursor solution used in this work favors the formation of a predominantly hexagonal phase. Similar outcomes have been reported by several research groups in CdS thin films obtained by chemical bath deposition in basic medium [22-24]. On the contrary, note that, in the XRD patterns for the samples L1, L2, L3, and L4, neither $\mathrm{CuS}$ nor $\mathrm{Cu}_{2} \mathrm{~S}$ diffraction maxima are observed, indicating that these phases were not formed during the immersion process.

From the XRD analysis, we can observe two important effects in the principal (002) reflection as immersion time of the sample within the cationic solution increases: (i) it is slightly shifted to larger values of 2-theta and (ii) its intensity decreases. This can be explained as follows: the copper atoms present in the cationic solution can replace the $\mathrm{Cd}$ atoms ligated within the crystal lattice of the CdS, producing substitutional doping [25]. The observed structural changes originate from the difference between the ionic radius of
TABLE 1: Cell parameters of CdS : Cu thin films obtained by XRD.

\begin{tabular}{lcccc}
\hline Sample & $a(\AA)$ & $c(\AA)$ & Cell volume $\left(\AA^{3}\right)$ & Crystallite size $(\mathrm{nm})$ \\
\hline L0 & 4.1053 & 6.6802 & 112.58 & 26.2 \\
L1 & 4.1053 & 6.6587 & 112.22 & 21.8 \\
L2 & 4.1053 & 6.6594 & 112.23 & 25.7 \\
L3 & 4.1053 & 6.6643 & 112.32 & 22.8 \\
L4 & 4.1053 & 6.6615 & 112.27 & 27.9 \\
\hline
\end{tabular}

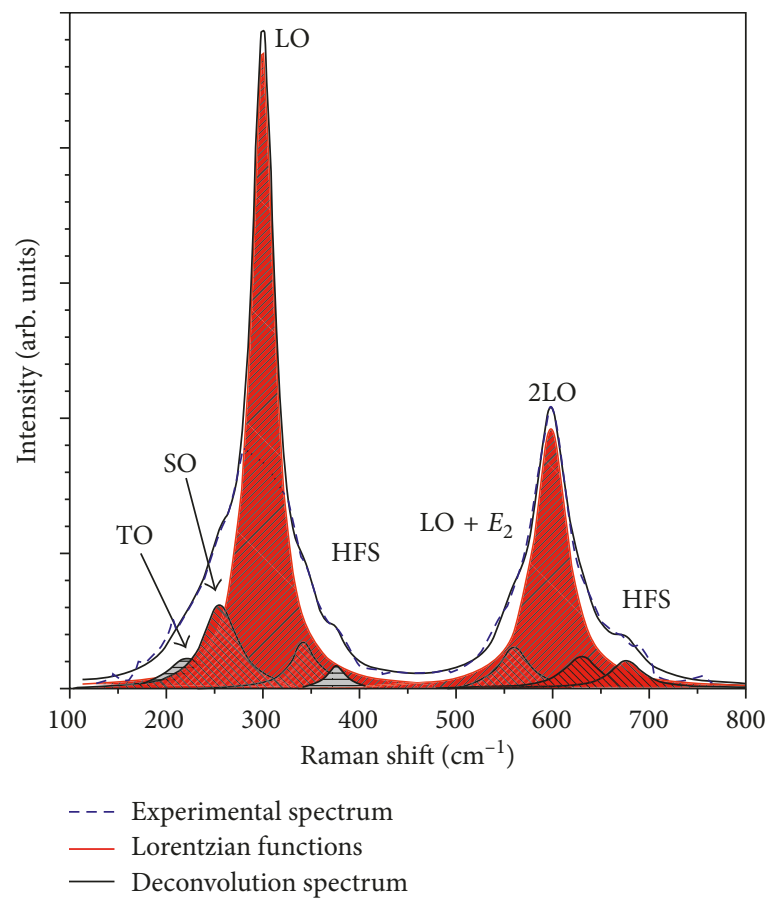

Figure 2: Deconvolution of the Raman spectra for the CdS reference film (L0).

both cations $\left(\mathrm{Cu}^{2+}=87 \mathrm{pm}\right.$ and $\left.\mathrm{Cd}^{2+}=109 \mathrm{pm}\right)$. According to Bragg's law, the slight shift of the (002) diffraction peak towards larger values of 2-theta is related with the shrinkage of the c lattice constant of the hexagonal cell, which can be explained by the substitution of $\mathrm{Cd}$ cations by smaller $\mathrm{Cu}$ ones in the CdS crystalline lattice. On the contrary, the substitution of the $\mathrm{Cd}$ atoms by $\mathrm{Cu}$ atoms promotes disorder into the crystalline host cell; consequently, the width and intensity of the (002) peak is affected directly by the orderdisorder effect $[26,27]$. These phenomena can be explained as follows: when the CdS films are immersed into the cationic solution, the $\mathrm{Cd}$ atoms are displaced from the crystalline host cell destabilizing their structure (disorder effect); subsequently, the vacancy sites are occupied by $\mathrm{Cu}$ atoms stabilizing the crystal lattice again (order effect).

The latter effect can be better observed in the inset of Figure 1, where a meaningful decrease in the (002) reflection intensity is observed during the first $45 \mathrm{~min}$ immersion; afterward at 60 and $75 \mathrm{~min}$, the (002) reflection intensity increases slightly, due to the reorder of the atoms as mentioned before. At $90 \mathrm{~min}$, a decrease is observed again owing to direct substitution of $\mathrm{Cd}$ atoms by $\mathrm{Cu}$ atoms $(\mathrm{Cu}$ radius $<\mathrm{Cd}$ radius). This situation can be validated through 
TABLE 2: Summary of centers and FWHM (in parentheses) for the different optical vibrational modes observed in all set Raman spectra.

\begin{tabular}{|c|c|c|c|c|c|c|c|c|c|}
\hline \multirow{2}{*}{ Sample } & \multicolumn{5}{|c|}{ Fundamental optical phonon } & \multicolumn{4}{|c|}{ First overtone } \\
\hline & $E_{1}(\mathrm{TO})$ & $E_{2}(\mathrm{SO})$ & $E_{1}(\mathrm{LO})$ & $E_{2}(\mathrm{~m})$ & $E_{2}(\mathrm{~m})$ & $E_{2}(\mathrm{~m})$ & $2 E_{1}(\mathrm{LO})$ & $2 E_{2}(\mathrm{~m})$ & $2 E_{2}(\mathrm{~m})$ \\
\hline L0 & $231.9(48.4)$ & $255.0(43.2)$ & 3000 (298 & $344.0(31.6$ & $375.4(21.3$ & $559.1(36.2)$ & & & $676.1(40.0)$ \\
\hline $\mathrm{L} 1$ & $4.1(34.8)$ & 7 & & & & & $598.7(35$ & & \\
\hline $\mathrm{L} 2$ & $235.4(37.2)$ & $258.2(33.8)$ & $300.7(26.2)$ & $343.9(38.0)$ & $379.9(28.5)$ & $557.6(35.3)$ & $599.8(41.0)$ & $635.6(41.2)$ & $675.7(36.4)$ \\
\hline L3 & $238.6(44.3)$ & $255.6(25.5)$ & $300.5(25.6)$ & $341.2(35.3)$ & $376.0(25.6)$ & $558.6(37.8)$ & $599.4(39.1)$ & $631.8(35.4)$ & $665.4(34.4)$ \\
\hline $\mathrm{L} 4$ & $235.8(33.0)$ & $253.6(43.2)$ & $301.0(29.5)$ & $344.4(31.9)$ & $377.2(26.3)$ & $562.2(30.6)$ & $598.7(39.4)$ & $630.4(41.8)$ & $672.6(34.2)$ \\
\hline
\end{tabular}

the difference observed in the crystalline parameters of the $\mathrm{CdS}$ : $\mathrm{Cu}$ films, determined from XRD patterns, using the Jade 9.7 software $^{\mathrm{TM}}$ (Table 1).

Here, a decrease in the " $c$ " parameter values, as well as in the cell volume, is observed in the sample immersed during $45 \mathrm{~min}$. With the increase of immersion time up to 60 and $75 \mathrm{~min}$, both parameters increase slightly, stabilizing the crystal cell. Finally, at $90 \mathrm{~min}$, a decrease of these parameters due to the shrinkage of the cell is observed, in agreement with Vegard's law.

Raman analysis of the different films was performed to evaluate the immersion time effect on the lattice vibrations of the CdS compound. According to the literature, the cadmium sulfide possesses a space group $\mathrm{P} 6_{3} \mathrm{mc}\left(\mathrm{C}_{6 \mathrm{Vv}}^{4}\right)$ with four atoms per unit cell. Hence, nine vibrations can be predicted at the zone-center optical phonon modes as follows: $2 A_{1}+1 A_{2}+1 B_{1}+1 B_{2}+2 E_{1}+2 E_{2}$, where six modes at the zone center $2 A_{1}+2 E_{1}+2 E_{2}$ are active in the Raman spectra $[28,29]$.

Figure 2 shows the deconvolution of the Raman spectrum for the CdS reference film, where two dominant optical vibrational modes located at 300 and $600 \mathrm{~cm}^{-1}$, approximately, are observed. These signals can be assigned to the fundamental longitudinal optical phonon mode $E_{1}(\mathrm{LO})$ and its first overtone mode (2LO), respectively $[28,29]$. Similar behavior has been observed in different II-VI family compounds studied under resonant conditions, which could explain the dominance of the LO mode and its overtone in the spectra $[30,31]$. Additionally, to improve the experimental data fitting, the spectrum in the regions around the LO and 2LO peaks was deconvoluted through several additional Lorentzian functions using the Fityk software ${ }^{\mathrm{TM}}$ [32]. The results revealed considerable asymmetry on the low and high frequency side in both optical modes (LO and 2LO). The identified principal vibrations modes as well as FWHM from this fitting are summarized in Table 2, which correspond mainly to a transversal optical (TO) and multiphonon modes [29, 33,34]. Similar approach as the one developed in the deconvolution of the reference sample spectrum has been used to fit the set of remaining Raman spectra (L1, L2, L3, and L4).

Figure 3 shows the set of Raman spectra of the different samples for their comparison. Each of these spectra was deconvoluted in nine Lorentzian line shape signals, which are observed at $235,255,300,344,370,560,598,630$, and $680 \mathrm{~cm}^{-1}$ approximately. Here, in all the spectra, a similar behavior can be detected, also that the LO and 2LO optical modes do not undergo any significant shift with the immersion time, maintaining their position near to 300 and

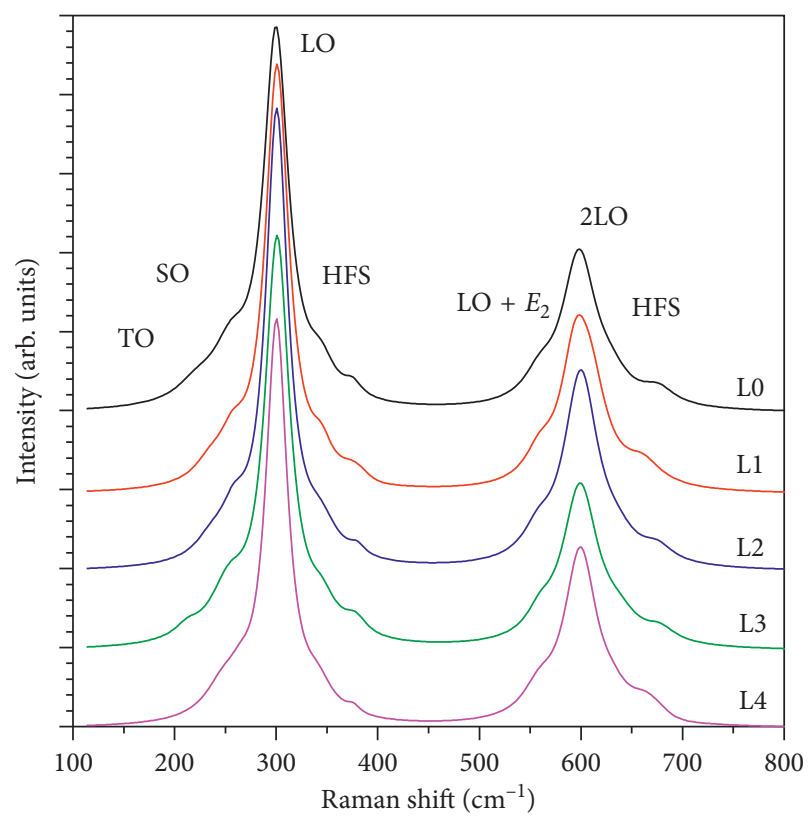

Figure 3: Raman spectra set obtained for the CdS: Cu films obtained by ionic exchange process in aqueous solution.

$598 \mathrm{~cm}^{-1}$, respectively (Table 2 ). The corresponding positions for the different optical vibrational modes observed in the complete set of samples and the results are collected in Table 2. According to the literature, the optical vibrations located at $\approx 235$ and $252 \mathrm{~cm}^{-1}$ can be classified as doubly degenerate $E_{1}(\mathrm{TO})$, while vibration observed at $\approx 254 \mathrm{~cm}^{-1}$ is commonly assigned either to surface optical (SO) or zoneedge (ZE) phonons (mainly in studies concerned with freestanding nanoparticles).

On the contrary, Raman bands located at 344,377 , and $560 \mathrm{~cm}^{-1}$ are the results from the active participation of the multiphonon scattering processes $E_{2}(\mathrm{~m})$ or some combination these modes. In this sense, the asymmetry in the high frequency side of the LO optical mode can be denoted as HFS (high-frequency shoulder) which assumes the combination of the Raman signals located at 344 and $377 \mathrm{~cm}^{-1}$, respectively, as proposed in the earlier literature $[31,35,36]$. Similarly, the low-frequency asymmetry of the 2LO mode $\left(344 \mathrm{~cm}^{-1}\right)$ can be assigned to combination of $\left(\mathrm{LO}+E_{2}\right)$ and/or $\left(\mathrm{LO}+E_{1} / \mathrm{TO}\right)$ modes, and similar assignments have been found in the literature for the SO mode, derived from the sum of frequency and shape [36].

The modes located at 630 and $680 \mathrm{~cm}^{-1}$ around the $2 \mathrm{LO}$ peak have been assigned similarly to the HFS of the LO one 


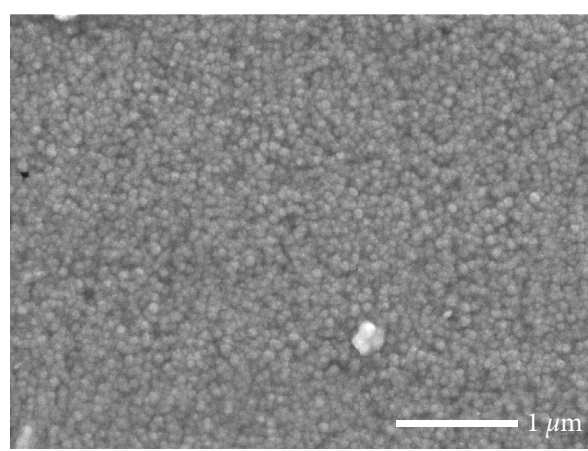

(a)

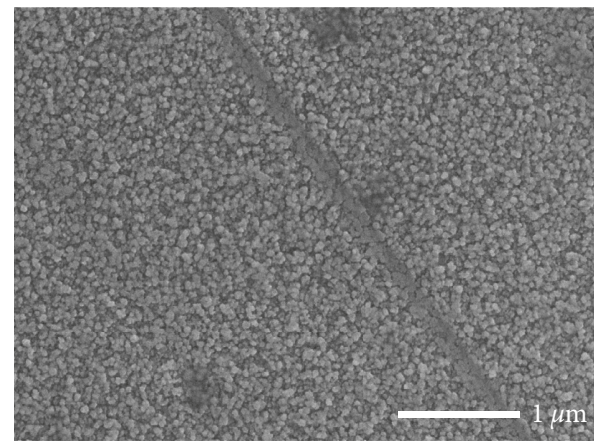

(c)

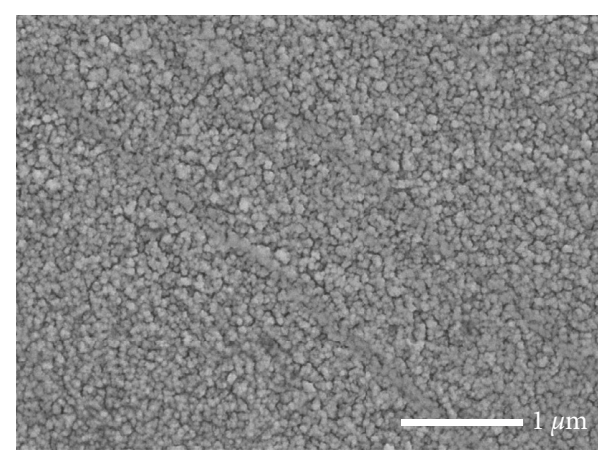

(b)

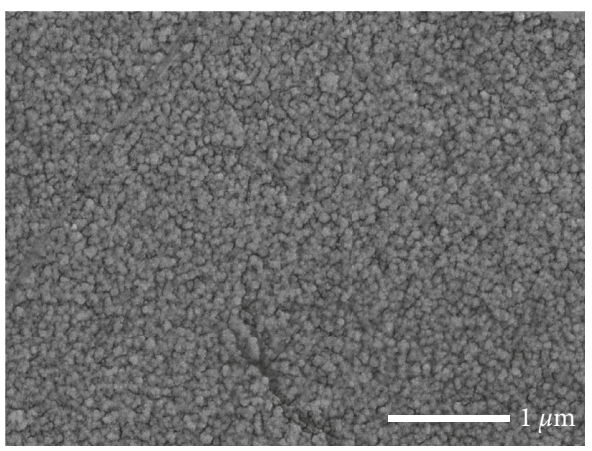

(d)

FIgURE 4: SEM images of CdS thin films placed into $\mathrm{CuCl}_{2}$ solution at different immersion times (a) CdS reference, (b) 60 min, (c) 75 min, and (d) $90 \mathrm{~min}$.

(combination of multiphonon processes) [36]. Finally, from Raman analysis it can be noted that both low- and highfrequency asymmetry correlates with the density of phononic states and therefore can be related with phonon modes (or their combinations) activated by surface of the grains, with the latter playing the role of disorder for bulk-like phonons as described by Han and Bester [37].

Note that in Figure 3, any feature related with the formation of copper sulfide phase during the immersion of the CdS films in the cationic solution are not displayed, since the vibrational modes corresponding to the S-S bonds (intense peak at $465 \mathrm{~cm}^{-1}$ ) are not displayed, and this evidence confirms that any copper sulfide phase was formed during the immersion of the CdS films in the cationic solution (or its amount is below the detection limit) [38-40].

\subsection{Morphological and Compositional Properties.} Figure 4 shows the SEM micrographs of some samples, including the CdS film reference. Figure 4(a) corresponds to the $\mathrm{CdS}$ reference. It can be observed that this sample presents a homogeneous distribution of particles with a compact and uniform appearance.

In Figures 4(b)-4(d), a clear change in the surface morphology is observed in the samples immersed during 60, 75 , and $90 \mathrm{~min}$, respectively. In these micrographs, an increase in the particle size as well as nonuniform agglomerates at perpendicular direction to substrate is observed. At $60 \mathrm{~min}$, it was detected that the immersion into the $\mathrm{CuCl}_{2}$ solution promotes a change in the particle size, yielding a change in the surface morphology of the sample. Also, at larger immersion times, the formation of nonuniform agglomerates is observed, promoting a rougher and less smooth surface. Similar morphologies have been observed in $\mathrm{Cu}_{\mathrm{x}} \mathrm{S}$ thin films obtained by chemical bath deposition, in particular our research group has reported similar morphologies in $\mathrm{Cu}_{\mathrm{x}} \mathrm{S}$ thin films obtained by ammonia-free process [41].

Hence, these changes might be associated directly to the $\mathrm{Cu}^{2+}$ atoms substitution (disorder effect), promoting mainly surface changes due to the deformation of the CdS crystalline lattice $[27,42]$. In this sense, the major amount of $\mathrm{Cu}^{2+}$ atoms will be distributed homogeneously over CdS film surface, despite this, the formation of $\mathrm{Cu}_{\mathrm{x}} \mathrm{S}$ compound was not promoted as demonstrated by X-ray diffraction and Raman spectroscopy.

WDS measurements were carried out by a "thick film analysis" to obtain quantitative information about the chemical composition of the different CdS-Cu films. Figure 5 shows an average concentration plot for the L0, L2, L3, and L4 samples. Note that the CdS film reference presents a Cd: S ratio equal to 1 . The $\mathrm{L} 2$ sample immersed during $45 \mathrm{~min}$ into $\mathrm{CuCl}_{2}$ solution shows a decrease of $3 \%$ in the $\mathrm{Cd}$ atoms, and the quantity which was replaced by $\mathrm{Cu}$ atoms maintained a similar proportion of S atoms $(\sim 50 \%)$ with respect to the reference. Additionally, a larger variability in the composition of this sample in comparison with the L3 and L4 samples can be seen indicating an aleatory substitution of the 


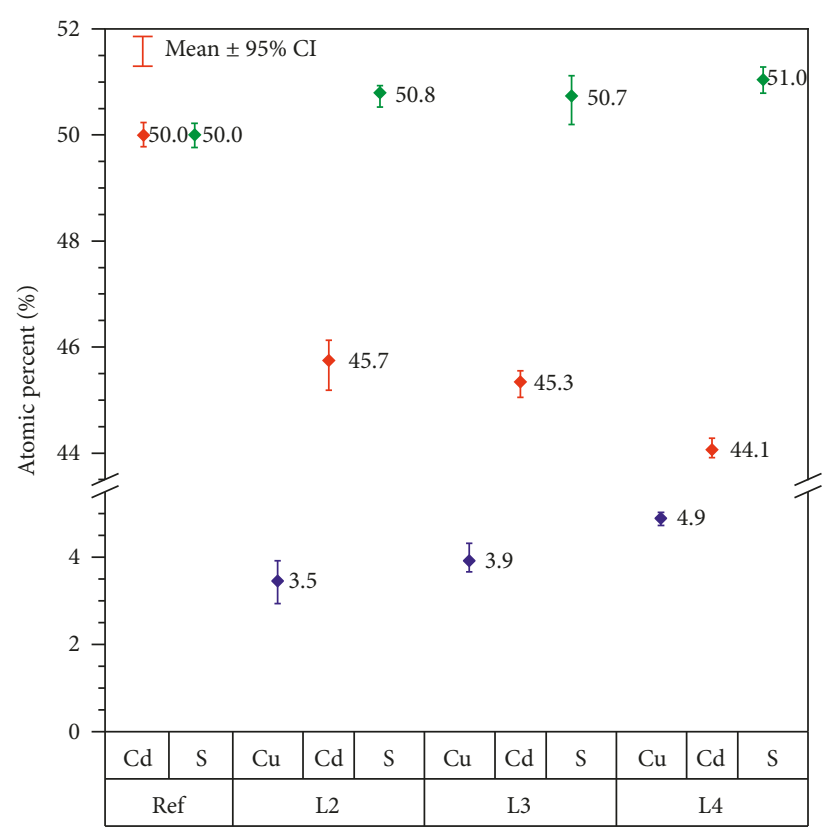

Figure 5: Elemental composition of $\mathrm{CdS}$ : $\mathrm{Cu}$ films obtained by ionic exchange process in aqueous solution.

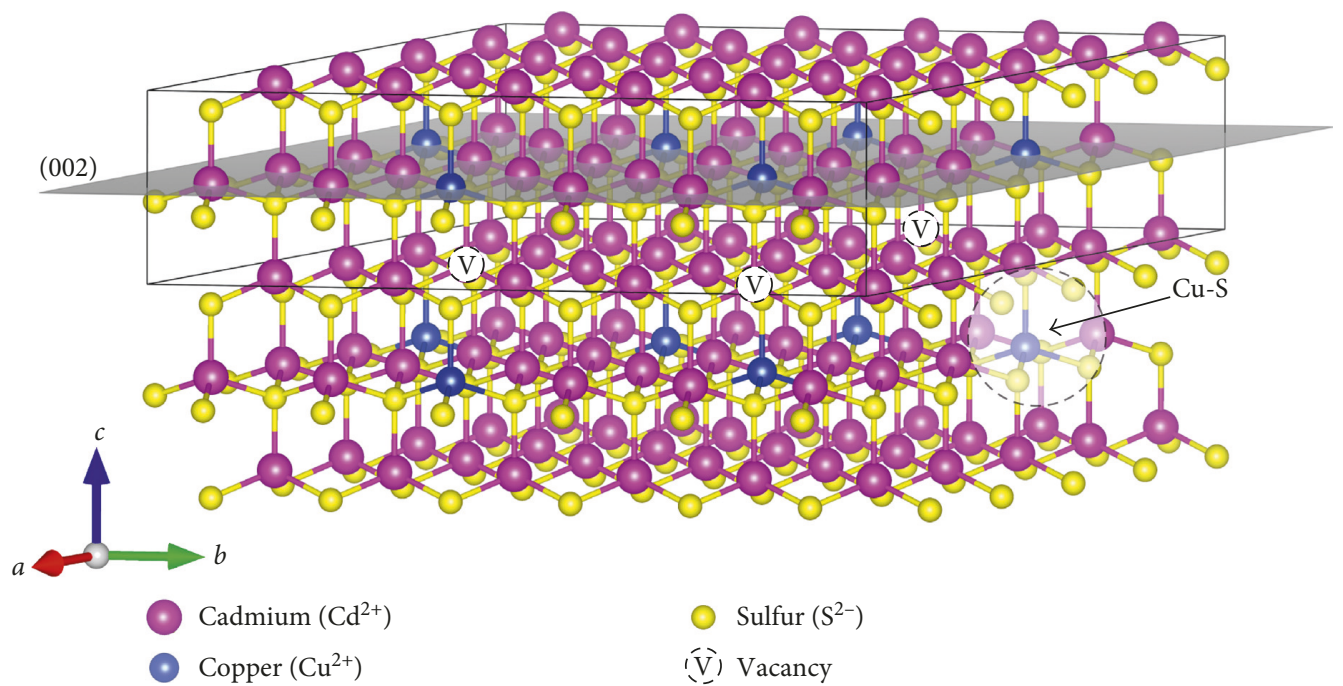

Figure 6: Schematic distribution of the $\mathrm{Cu}^{2+}$ atoms over the (002) plane within crystalline structure of CdS.

$\mathrm{Cu}^{2+}$ atoms within crystal host lattice. As the immersion time increases, this composition variability is reduced, and more cadmium atoms are replaced by copper atoms yielding a final composition of $\mathrm{Cd}_{0.95} \mathrm{Cu}_{0.05} \mathrm{~S}$ approximately (90 $\mathrm{min}$ ). That is, about $10 \%$ of $\mathrm{Cd}$ atoms were substituted during the longest immersion process. Nevertheless, some vacancies of $\mathrm{S}^{2-}$ can be generated during the immersion process, and this explains the variability observed in the mean plot for the sulfur atoms.

Therefore, based on the XRD patterns, Raman spectra, and WDS analysis, we suggest a scheme of the distribution of the $\mathrm{Cu}^{2+}$ atoms over the (002) planes in the CdS hexagonal structure as shown in Figure 6. Here, initially $\mathrm{Cu}$ atoms are distributed aleatory over the cadmium sulfide film surface deforming the crystalline structure (Figure 4(b)), subsequently, a larger quantity of cations is introduced into crystalline lattice stabilizing the crystal lattice again. Finally, at the longest immersion time, ten percent of the $\mathrm{Cd}$ atoms are substituted by $\mathrm{Cu}$ atoms inducing a decrease in the lattice parameters due to the shrinkage of the cell.

\section{Summary and Conclusions}

We have described a possible mechanism for the incorporation of copper atoms into the structure of CdS thin films by a simple ion exchange process, using an ammoniumfree chemical bath deposit process and a subsequent immersion in a $\mathrm{CuCl}_{2}$ solution at $45,60,75$, and $90 \mathrm{~min}$, to 
achieve the ion exchange, generating $\mathrm{Cd}_{\mathrm{x}} \mathrm{Cu}_{1-\mathrm{x}} \mathrm{S}$ films. A first indicative of the change in the chemical composition was followed by the change in color from yellowish to greenish.

The X-ray analysis suggested that the CdS films developed a hexagonal structure, with preferential orientation along the plane (002), corroborated by the presence of one reflection located at $2 \theta \approx 48^{\circ}$, which explicitly corresponds to the (103) reflection of the hexagonal phase of CdS. During the ion exchange, a decrease in the intensity of the reflection (002) was observed as well as a slight displacement of this reflection towards higher values of $2 \theta$ derived from the substitution of $\mathrm{Cd}$ atoms by $\mathrm{Cu}$ atoms. The WDS analysis revealed that approximately $10 \%$ of the cadmium atoms were replaced by copper atoms after $90 \mathrm{~min}$ of immersion.

\section{Data Availability}

The data underlying the conclusions of the article are available upon request.

\section{Conflicts of Interest}

The authors declare that they have no conflicts of interest.

\section{Acknowledgments}

The technical assistance of Adair Jimenez-Nieto and the use of LIDTRA facilities are gratefully acknowledged. E. FloresGarcía wishes to thank CONACYT-Mexico for a Ph.D. Grant no. 403729.

\section{References}

[1] O. Madelung, II-VI Compounds Semiconductors: Data Handbook, Springer-Verlag, Berlin, Heidelberg, Germany, 2004.

[2] A. K. Singh, S. Mehra, and G. S. Thool, "Synthesis of copper sulphide (CuS) thin film by chemical bath deposition method and its characterisation," European Chemical Bulletin, vol. 2, pp. 518-523, 2013.

[3] S. Prabahar and M. Dhanam, "CdS thin films from two different chemical baths-structural and optical analysis," Journal of Crystal Growth, vol. 285, no. 1-2, pp. 41-48, 2005.

[4] R. Castro-Rodríguez, A. I. Oliva, V. Sosa, F. CaballeroBriones, and J. L. Peña, "Effect of indium tin oxide substrate roughness on the morphology, structural and optical properties of CdS thin films," Applied Surface Science, vol. 161, no. 3-4, pp. 340-346, 2000.

[5] D. Sreekantha Reddy, K. Narasimha Rao, K. R. Gunasekhar, Y. Dwarakanadha Reddy, and P. Sreedhara Reddy, "Synthesis and dc magnetic susceptibility of the diluted magnetic semiconducting Cd1-xMnxS nanocrystalline films," Journal of Alloys and Compounds, vol. 461, no. 1-2, pp. 34-38, 2008.

[6] B. S. Moon, J. H. Lee, and H. Jung, "Comparative studies of the properties of CdS films deposited on different substrates by R. F. sputtering," Thin Solid Films, vol. 511-512, pp. 299-303, 2006.

[7] P. Boieriu, R. Sporken, A. Adriaens, Y. Xin, N. D. Browning, and S. Sivananthan, "SIMS and XPS characterization of CdS/ CdTe heterostructures grown by MBE," Nuclear Instruments and Methods in Physics Research Section B: Beam Interactions with Materials and Atoms, vol. 161-163, pp. 975-979, 2000.
[8] E. W. Jones, V. Barrioz, S. J. C. Irvine, and D. Lamb, “Towards ultra-thin CdTe solar cells using MOCVD," Thin Solid Films, vol. 517, no. 7, pp. 2226-2230, 2009.

[9] J. M. Nel, H. L. Gaigher, and F. D. Auret, "Microstructures of electrodeposited CdS layers," Thin Solid Films, vol. 436, no. 2, pp. 186-195, 2003.

[10] M. Sağlam, A. Ateş, B. Güzeldir, A. Astam, and M. A. Yildirim, "Effects of thermal annealing on electrical characteristics of $\mathrm{Cd} / \mathrm{CdS} / \mathrm{n}-\mathrm{Si} / \mathrm{Au}-\mathrm{Sb}$ sandwich structure," Journal of Alloys and Compounds, vol. 484, no. 1-2, pp. 570-574, 2009.

[11] J. K. Dongre and M. Ramrakhiani, "Synthesis of flower-like CdS nanostructured films and their application in photoelectrochemical solar cells," Journal of Alloys and Compounds, vol. 487 , no. 1-2, pp. 653-658, 2009.

[12] R. S. Mane and C. D. Lokhande, "Chemical deposition method for metal chalcogenide thin films," Materials Chemistry and Physics, vol. 65, no. 1, pp. 1-31, 2000.

[13] P. O'Brien and J. McAleese, "Developing an understanding of the processes controlling the chemical bath deposition of $\mathrm{ZnS}$ and CdS," Journal of Materials Chemistry, vol. 8, no. 11, pp. 2309-2314, 1998.

[14] T. J. Coutts, "High efficiency solar cells with CdS window layers," Thin Solid Films, vol. 90, no. 4, pp. 451-460, 1982.

[15] G. Sasikala, P. Thilakan, and C. Subramanian, "Modification in the chemical bath deposition apparatus, growth and characterization of CdS semiconducting thin films for photovoltaic applications," Solar Energy Materials and Solar Cells, vol. 62 , no. 3, pp. 275-293, 2000.

[16] F. J. Bryant, A. K. Hariri, S. Salkalachen, and C. G. Scott, "Annealing and diffusion processes in thin film $\mathrm{CdS} / \mathrm{Cu} 2 \mathrm{~S}$ solar cells," Thin Solid Films, vol. 105, no. 4, pp. 343-351, 1983.

[17] T. J. Cumberbatch, P. E. Barden, and J. Durrant, "A new approach to the fabrication of cuprous sulphide-cadmium sulphide solar cells," Thin Solid Films, vol. 167, no. 1-2, pp. 169-174, 1988.

[18] S. Saksea, D. K. Pandya, and K. L. Chopra, "Electroconversion of CdS to CuxS for thin film solar cells," Thin Solid Films, vol. 94, no. 3, pp. 223-232, 1982.

[19] R. Mariappan, V. Ponnuswamy, M. Ragavendar, D. Krishnamoorthi, and C. Sankar, "The effect of annealing temperature on structural and optical properties of undoped and $\mathrm{Cu}$ doped CdS thin films," Optik-International Journal for Light and Electron Optics, vol. 123, no. 12, pp. 1098-1102, 2012.

[20] P. Reyes and S. Velumani, "Structural and optical characterization of mechanochemically synthesized copper doped CdS nanopowders," Materials Science and Engineering: B, vol. 177, no. 16, pp. 1452-1459, 2012.

[21] M. G. Sandoval-Paz, M. Sotelo-Lerma, A. Mendoza-Galvan, and R. Ramírez-Bon, "Optical properties and layer microstructure of CdS films obtained from an ammonia-free chemical bath deposition process," Thin Solid Films, vol. 515, no. 7-8, pp. 3356-3362, 2007.

[22] M. B. Ortuño López, J. J. Valenzuela-Jáuregui, M. SoteloLerma, A. Mendoza-Galván, and R. Ramírez-Bon, "Highly oriented CdS films deposited by an ammonia-free chemical bath method," Thin Solid Films, vol. 429, no. 1-2, pp. 34-39, 2003.

[23] I. Carreón-Moncada, L. A. González, J. L. Rodríguez-Galicia, and J. C. Rendón-Angeles, "Chemical deposition of CdS films by an ammonia-free process with amino acids as complexing agents," Thin Solid Films, vol. 599, pp. 166-173, 2016. 
[24] O. P. Moreno, R. G. Pérez, M. C. Portillo et al., "Morphological, optical and structural analysis in CdS, CdS-CdCO 3 and CdCO 3 thin solid films grown by chemical bath," Optik, vol. 157, pp. 388-399, 2018.

[25] B. J. Beberwyck, Y. Surendranath, and A. P. Alivisatos, "Cation exchange: a versatile tool for nanomaterials synthesis," Journal of Physical Chemistry C, vol. 117, no. 39, pp. 19759-19770, 2013.

[26] Y. Deng, J. Yang, R. Yang, K. Shen, D. Wang, and D. Wang, "Cu-doped CdS and its application in CdTe thin film solar cell,” AIP Advances, vol. 6, no. 1, article 015203, 2016.

[27] R. Xie, J. Su, M. Li, and L. Guo, "2013 structural and photoelectrochemical properties of $\mathrm{Cu}$-doped $\mathrm{CdS}$ thin films prepared by ultrasonic spray pyrolysis," International Journal of Photoenergy, vol. 2013, Article ID 620134, 7 pages, 2013.

[28] R. J. Briggs and A. K. Ramdas, "Piezospectroscopic study of the Raman spectrum of cadmium sulfide," Physical Review B, vol. 13, no. 12, pp. 5518-5529, 1976.

[29] B. Tell, T. C. Damen, and S. P. S. Porto, "Raman effect in cadmium sulfide," Physical Review, vol. 144, no. 2, pp. 771774, 1966.

[30] R. C. C. Leite, J. F. Scott, and T. C. Damen, "Multiple-phonon resonant Raman scattering in CdS," Physical Review Letters, vol. 22, no. 15, pp. 780-782, 1969.

[31] V. M. Dzhagan, M. Y. Valakh, C. Himcinschi et al., "Raman and infrared phonon spectra of ultrasmall colloidal CdS nanoparticles," Journal of Physical Chemistry C, vol. 118, no. 33, pp. 19492-19497, 2014.

[32] M. Wojdyr, "Fityk: a general-purpose peak fitting program," Journal of Applied Crystallography, vol. 43, no. 5, pp. 1126$1128,2010$.

[33] V. M. Dzhagan, M. Y. Valakh, A. G. Milekhin et al., "Ramanand IR-active phonons in CdSe/CdS core/shell nanocrystals in the presence of interface alloying and strain," Journal of Physical Chemistry C, vol. 117, no. 35, pp. 18225-18233, 2013.

[34] P. Kumar, N. Saxena, R. Chandra, V. Gupta, A. Agarwal, and D. Kanjilal, "Nanotwinning and structural phase transition in CdS quantum dots," Nanoscale Research Letters, vol. 7, no. 1, p. 584, 2012.

[35] Q. Zhang, J. Zhang, M. I. B. Utama et al., "Exciton-phonon coupling in individual ZnTe nanorods studied by resonant Raman spectroscopy," Physical Review B, vol. 85, no. 8, pp. 1-9, 2012.

[36] V. Dzhagan, M. Valakh, N. Mel'nik et al., "2012 phonon spectra of small colloidal II-VI semiconductor nanocrystals," International Journal of Spectroscopy, vol. 2012, Article ID 532385, 6 pages, 2012.

[37] P. Han and G. Bester, "Confinement effects on the vibrational properties of III-V and II-VI nanoclusters," Physical Review B, vol. 85, no. 4, pp. 1-4, 2012.

[38] N. A. Yeryukov, A. G. Milekhin, L. L. Sveshnikova et al., "Synthesis and characterization of CuxS $(\mathrm{x}=1-2)$ nanocrystals formed by the Langmuir-Blodgett technique," Journal of Physical Chemistry C, vol. 118, no. 40, pp. 23409-23414, 2014.

[39] M. Ishii, K. Shibata, and H. Nozaki, "Anion distributions and phase transitions in CuS1-xSex $(\mathrm{x}=0-1)$ studied by Raman spectroscopy," Journal of Solid State Chemistry, vol. 105, no. 2, pp. 504-511, 1993.

[40] C. G. Munce, G. K. Parker, S. A. Holt, and G. A. Hope, "A Raman spectroelectrochemical investigation of chemical bath deposited CuxS thin films and their modification," Colloids and Surfaces A: Physicochemical and Engineering Aspects, vol. 295, no. 1-3, pp. 152-158, 2007.
[41] E. Flores-García, P. González-García, J. González-Hernández, and R. Ramírez-Bon, "Non-toxic growth of CuxS thin films in alkaline medium by ammonia free chemical bath deposition," Optik-International Journal for Light and Electron Optics, vol. 145, pp. 589-598, 2017.

[42] W. R. Cook, L. Shiozawa, and F. Augustine, "Relationship of copper sulfide and cadmium sulfide phases," Journal of Applied Physics, vol. 41, no. 7, pp. 3058-3063, 1970. 

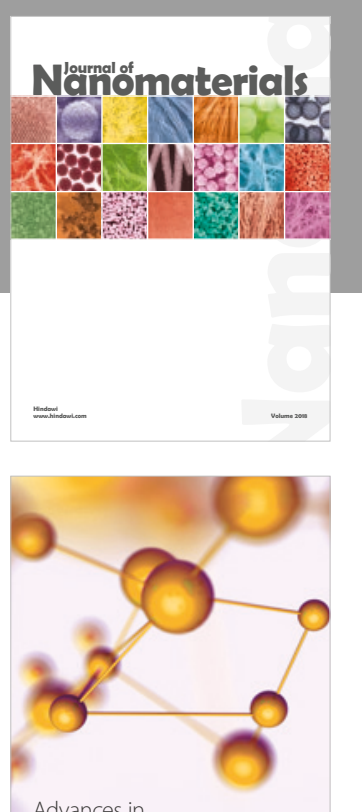

Physical Chemistry
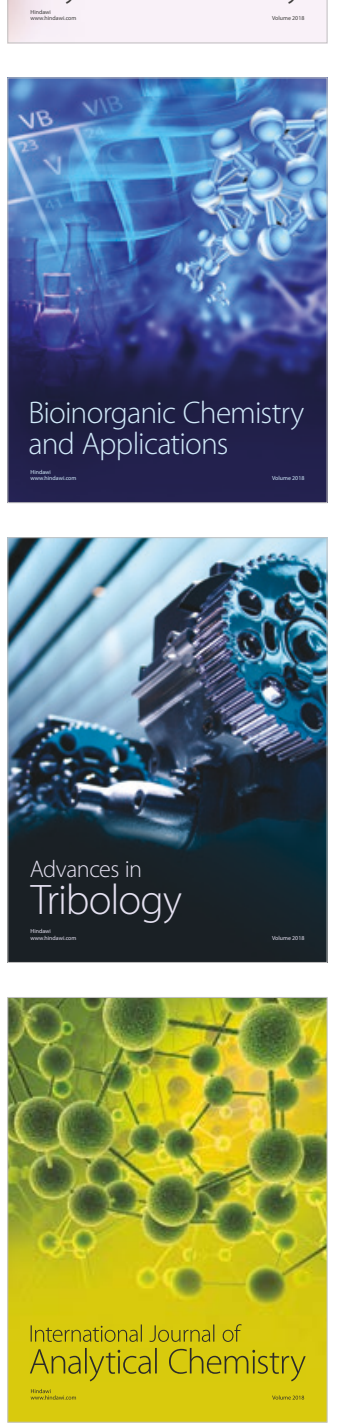

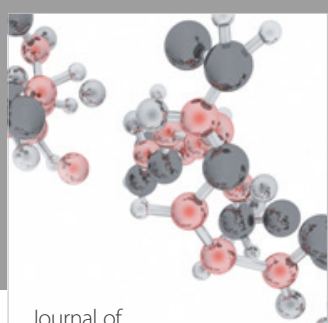

Analytical Methods

in Chemistry

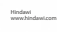

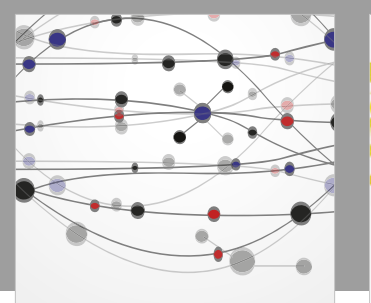

The Scientific World Journal

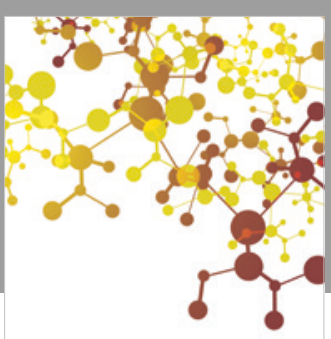

Journal of

Applied Chemistry
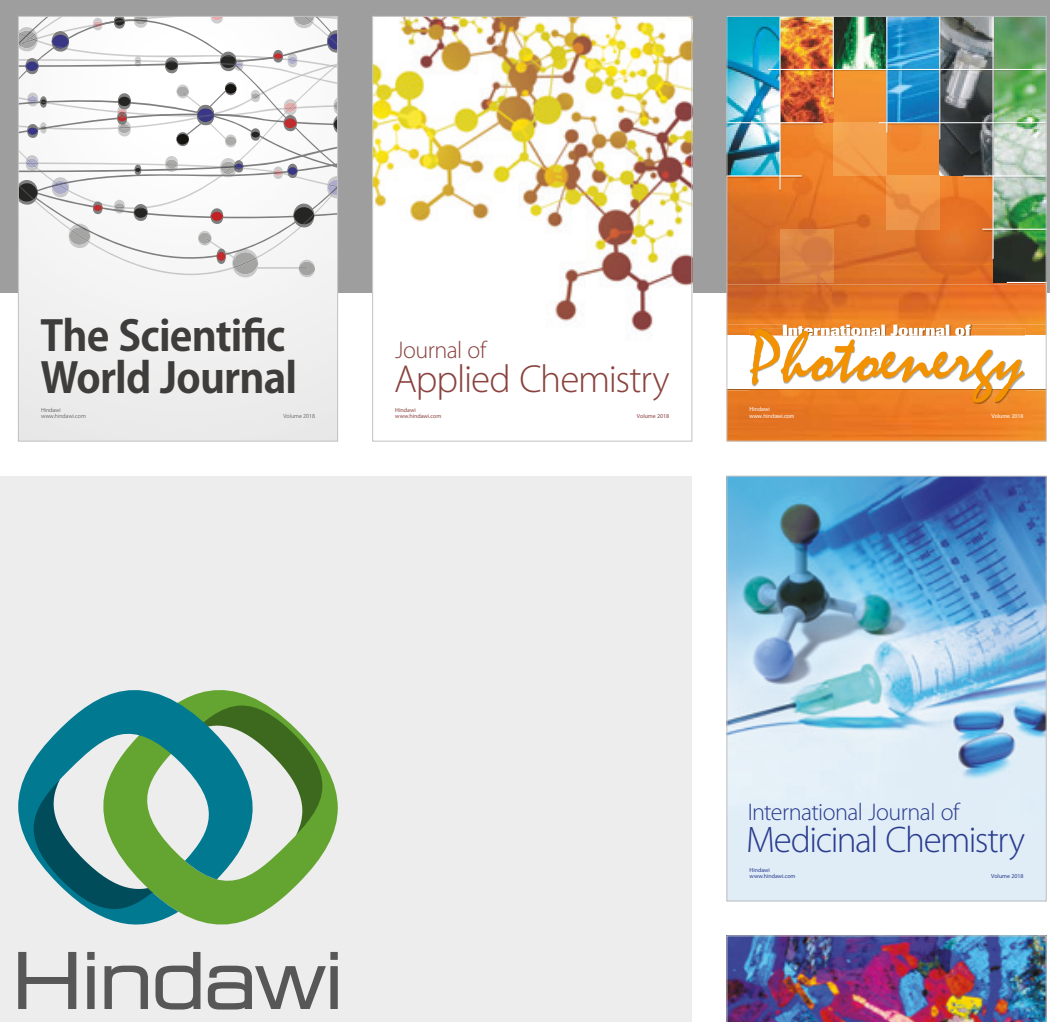

Submit your manuscripts at

www.hindawi.com
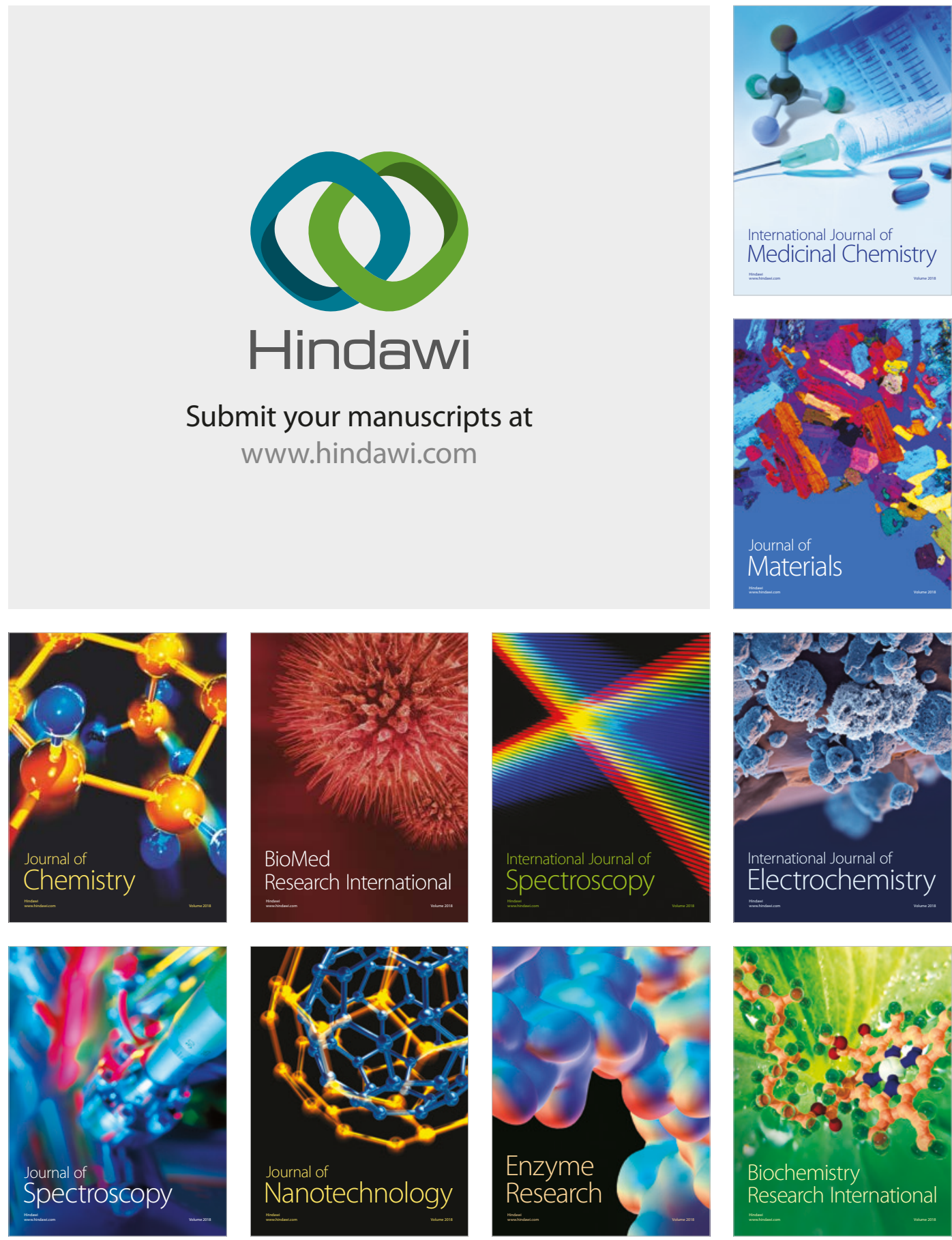
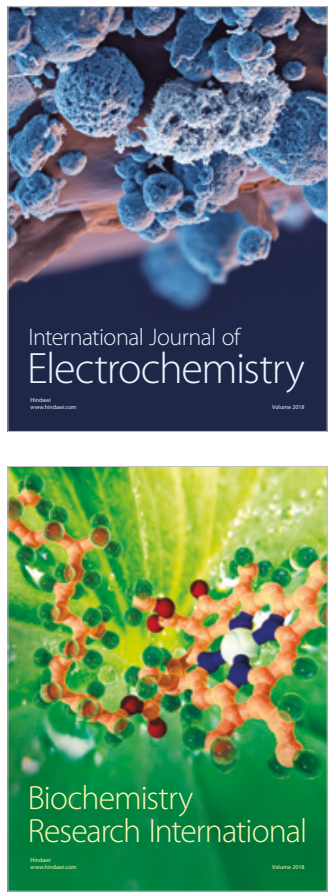